Available online on 15.01.2017 at http://jddtonline.info
O 2016, publisher and licensee JDDT, This is an Open Access article which permits unrestricted
noncommercial use, provided the original work is properly cited

Research Article

\title{
IN-VITRO RELEASE STUDY AND ANTIMICROBIAL PROPERTY EVALUATION OF OFLOXACIN LOADED POLY (2-HYDROXYETHYL METHACRYLATE) / POLY (CAPROLACTONE) / POLY (ETHYLENE GLYCOL) HYDROGEL SYSTEM FOR BURN WOUND MANAGEMENT
}

\section{Pandikkappallil Kumaran Rethikala ${ }^{1}$, Renjith $\mathrm{P} \mathrm{Nair}^{2}$, Lissy Kalliyana Krishnan ${ }^{2}$ and Venkiteswaran Kalliyana Krishnan*1}

${ }^{1}$ Division of Dental Products, Biomedical Technology Wing, Sree Chitra Tirunal Institute for Medical Sciences \& Technology, Poojappura, Trivandrum 695012, India

${ }^{2}$ Thrombosis Research Unit, Biomedical Technology Wing, Sree Chitra Tirunal Institute for Medical Sciences \& Technology, Poojappura, Trivandrum 695012, India

\begin{abstract}
Monomer 2-hydroxy ethyl methacrylate containing small amounts of poly(caprolactone) and poly(ethylene glycol) incorporated with an antibiotic ofloxacin was polymerized by photopolymerization technique using 2,4,6 trimethyl benzoyl diphenyl phosphine oxide (TPO) as photoinitiator. Encapsulation efficiency and in vitro drug release was studied using UV-visible spectroscopy. Swelling analysis was resorted to compare fluid uptake ability of hydrogel containing the drug with bare polymer. Zone of inhibition assay showed hydrogel containing $1 \%$ Ofloxacin to possess strong antimicrobial property Hemolysis assay demonstrated the hydrogel system to be non-hemolytic. Non-cytotoxic character of the hydrogel was confirmed using fibroblast cells. Cell adhesion studies showed non-attachment of fibroblasts to the polymer and improved cell proliferation simultaneously.
\end{abstract}

Key words: Ofloxacin, Encapsulation efficiency, Hydrogel, Antimicrobial

Article Info

Received 13 Nov 2016; Review Completed 14 Dec 2016; Accepted 15 Dec 2016, Available online 15 Jan 2017

Cite this article as:

Rethikala PK, Nair R, Krishnan LK, Krishnan VK, In-vitro release study and antimicrobial property evaluation of ofloxacin loaded poly (2hydroxyethyl methacrylate)/poly (caprolactone)/poly (ethylene glycol) hydrogel system for burn wound management, Journal of Drug Delivery and Therapeutics. 2017; 7(1):13-20, DOI: http://dx.doi.org/10.22270/jddt.v7i1.1351

*Corresponding author:

Venkiteswaran Kalliyana Krishnan, Division of Dental Products, Biomedical Technology Wing, Sree Chitra Tirunal Institute for Medical Sciences \& Technology, Poojappura, Trivandrum 695012, India, Mail ID: muralimanasi@ gmail.com, Phone: 91-471-2520221, 91-9447134060

\section{INTRODUCTION}

Burns are considered as one of the major health problems in the world, which accounts for nearly 2,65,000 deaths per annum. They tend to differ from other types of wounds exhibiting large amounts of nonviable tissue, exudation of tissue fluids, serum and blood, exposed for extended periods and exhibiting colonization of pathogenic bacteria. It is understood that infection of burn wounds is the main cause of increased rate of mortality and morbidity. Bacterial strains associated with burn wounds have been reported to change with time. ${ }^{1}$ Both gram-negative and grampositive bacteria are responsible for burn wound infection. Topical antimicrobial agents such as silver sulphadiazine are generally used to prevent infection and at the same time, the wound needs to be kept closed to prevent the invasion of microbes.

Hydrogel materials have earlier proved its excellence in wound dressing applications. ${ }^{2-6}$ It has the capacity to absorb wound exudates, make the wound clean and impart a moist environment, which facilitates healing. Hydrogel matrix incorporated with an antibiotic/antimicrobial agent is highly recommended for the treatment of an infected burn wound. Some of the reported novel antimicrobial wound dressings are gelatin hydrogel pads containing silver nanoparticles, chitosan 
with nano-ZnO, PVA-PVP hydrogel with seaweed extract and silver nanoparticle , poly(2-hydroxy ethyl methacrylate (pHEMA) hydrogel with ciprofloxacin. ${ }^{7}$ Ofloxacin (9-fluoro-2,3-dihydro-3-methyl -10 -(4methyl-1- piperazinyl)-7 oxo-7H- pyrido [1,2,3-de]-1,4benzoxazine-6-carboxylic acid) is a second generation fluoroquinolone antibiotic. It exhibits a broad spectrum of antibiotic property against gram-positive and gramnegative bacteria due to the presence of pyridine carboxylic acid group and is effectively used clinically for treating wound infections. ${ }^{8-9}$ Ofloxacin also inhibits the DNA replication by binding with enzymes DNA gyrase and topoisomerase IV which may eventually lead to the death of the microbe. Aqueous solution of ofloxacin shows absorption maxima at $293 \mathrm{~nm}$ corresponding to the carbonyl and carboxylic chromophores and the nitrogen of the piperazinyl group. This specific spectral aspect was used for the quantitative analysis during the in vitro drug release studies.

In our previous work, we have reported the development cytocompatible and non-adherent hydrogel wound dressing material based on pHEMA-PCL-PEG with good swelling and handling property. ${ }^{10}$ As infection is the major concern of burn wounds, incorporation of the antimicrobial agent into the above system is envisaged in this study in order to improve the infection control property. Ofloxacin in pHEMA-PCL-PEG hydrogel system is expected to augment the acceptance of pHEMA-PCL-PEG as a wound dressing material due to its antibiotic property. We have discussed here the preparation of this novel hydrogel, its characterization, the in vitro drug release profile of antibiotic from the hydrogel and the antimicrobial property demonstrated against gram-negative $E$. coli and gram-positive $S$. aureus.

\section{MATERIALS AND METHODS}

\section{Materials}

2-hydroxyethylmethacrylate [HEMA], 2, 4, 6 Trimethyl Benzoyl Diphenyl Phosphine oxide (TPO) and Polycaprolactone (PCL, $\mathrm{M}_{\mathrm{w}}$ 14,000), Ofloxacin (OFX) were all procured from Sigma-Aldrich Chemical Company Inc.(USA). Monomer HEMA was vacuum distilled before use. Polyethylene glycol (PEG, MW200) and formaldehyde were procured from Merck,Germany. Iscove's modified Dulbecco's Minimal Essential Medium - F12, Antibiotic-antimycotic solution, Foetal Bovine Calf Serum, Typsin-EDTA (all cell culture grade) were obtained from Invitrogen, USA. Acridin orange, Ethidium bromide Texas red phalloidin were obtained from Molecular Probes (USA). All reagents used were of analytical or equivalent grade. Phosphate buffered saline (PBS, pH 7.4) was prepared by dissolving $17.9 \mathrm{~g}$ of di-sodium hydrogen phosphate, $5.73 \mathrm{~g}$ of monosodium hydrogen phosphate and $9 \mathrm{~g}$ of sodium chloride in $1 \mathrm{~L}$ distilled water. Photopolymerization was carried out using a dental light cure unit containing a halogen bulb (Model 301, Prolite, Caulk/Dentsply, Melfork, DE, USA) of wavelength 380$480 \mathrm{~nm}$ was used for photo-curing the monomer.

\section{Preparation of ofloxacin incorporated hydrogel-using photopolymerization}

General methods for loading a drug into a hydrogel system have been reported earlier. ${ }^{11}$ In the present work, ofloxacin incorporated hydrogel was prepared using photo-polymerization as per patented procedure. ${ }^{12}$ PCL and PEG were added to the HEMA monomer, heated to $70-75^{\circ} \mathrm{C}$ until a homogenous mix is obtained, antibiotic drug Ofloxacin was added to the homogenous mix followed by the addition of $1 \mathrm{wt} \%$ TPO with constant stirring. After about $5 \mathrm{~min}$, the solution was poured into a teflon mold (60 $\mathrm{mm} \times 10 \mathrm{~mm} \times 1 \mathrm{~mm})$ and exposed to a dental light source for 3-5 minutes. After photo curing was complete, the mold containing the cured polymer was kept in distilled water for maximum of $2 \mathrm{hrs}$ to facilitate easy removal of the cured polymer. Table 1 shows details of the hydrogel systems prepared.

Table 1: Sample code and composition of polymeric hydrogels

\begin{tabular}{|l|c|c|c|c|}
\hline \multirow{2}{*}{$\begin{array}{l}\text { Sample } \\
\text { Code }\end{array}$} & \multicolumn{3}{|c|}{ Wt \% } & Drug (Wt\%) \\
\cline { 2 - 5 } & HEMA & PCL & PEG & Ofloxacin \\
\hline Hdrg-0.25 & 85 & 10 & 5 & 0.25 \\
\hline Hdrg-0.5 & 85 & 10 & 5 & 0.5 \\
\hline Hdrg-0.75 & 85 & 10 & 5 & 0.75 \\
\hline Hdrg-1.0 & 85 & 10 & 5 & 1.0 \\
\hline HI-3 & 85 & 10 & 5 & 0 \\
\hline
\end{tabular}

\section{Swelling studies}

Swelling study is important as fluid absorbing capacity is one of the important properties of hydrogel which provides a moisture environment over the wound bed. Pre-weighed lyophilised samples of Hdrg1 having dimensions $6 \mathrm{~mm} \times 1 \mathrm{~mm}$ were immersed in de-ionized water at $37^{\circ} \mathrm{C}$ for 24 hours. After removing the adherent water, the swollen samples were again weighed at specific intervals of time using an analytical balance
(Model CP224S, Sartorius, Germany) having a sensitivity of $0.1 \mathrm{mg}$. The swelling percentage of the samples were determined according to the following equation

Percentage swelling, $\mathrm{S} \%=\left\{\left[\mathrm{W}_{\mathrm{s}}-\mathrm{W}_{\mathrm{o}}\right] / \mathrm{W}_{\mathrm{o}}\right\} \times 100$.

where $\mathrm{W}_{\mathrm{s}}$ and $\mathrm{W}_{\mathrm{o}}$ are the masses of the swollen and dry samples respectively 


\section{Surface Wettability Studies}

Surface wettability of the dried hydrogel systems was determined via the sessile drop method using a videoassisted contact angle measuring device (Data Physics OCA15 plus, Germany) and imaging software (SCA20 software,Germany). Within 10 seconds of introduction of the DI/W droplets, the contact angle formed between the sessile droplets and the matrix was measured. The contact angle is expressed as an average value of four independent measurements taken at different sites on each matrix.

\section{Encapsulation Efficiency}

About 4mg of lyophilized and powdered Hdrg1 was incubated with $100 \mathrm{ml}$ of PBS for complete swelling. The mixture was transferred to a $50 \mathrm{ml}$ centrifuging tube and agitated using a sonicator (Bandelin Sonorex Digitec ,Germany) for 10 minutes. After centrifugation (2000 rpm, 10 minutes), the supernatant solution was analyzed using UV-Visible spectroscopy (Shimadzu, Japan) at a wavelength of $293 \mathrm{~nm}$. Drug encapsulation efficiency was calculated using the following equation:

\section{Drug Encapsulation Efficiency $=$}

Amount of drug present in the matrix

$\longrightarrow \times 100$

Theoretical amount of drug loade

\section{In vitro release profile of $\mathrm{OFX}$ drug}

Total immersion method was used to study the in vitro release of ofloxacin drug from cured and swollen hydrogel systems. After removal from the Teflon mold, hydrogel discs of $6 \mathrm{~mm}$ diameter and $1 \mathrm{~mm}$ thickness were punched out and incubated with $2 \mathrm{ml}$ PBS buffer (pH 7.4) in a shaking incubator at $37^{\circ} \mathrm{C}$ and $50 \mathrm{rpm}$ for $24 \mathrm{hr}$. After every $24 \mathrm{hr}$, UV absorbance was measured and equal volume of buffer replaced with the fresh buffer at each measurement time points. Readings were taken upto $120 \mathrm{hr}$ at $24 \mathrm{hr}$ intervals. A calibration curve of ofloxacin was earlier carried out in the range of quantity, within which a linear relationship between the concentration and absorbance was realized. From the calibration curve, the eluted drug concentration was determined. The experiments were carried out in triplicates and reported as average values.

\section{Antimicrobial activity}

Antimicrobial activity assessment of the hydrogel systems Hdrg1.0 (Hydrogel systems with highest drug loading) and HI-3 (bare without drug) was carried out using Agar diffusion method based on ISO 20645:2004(E) procedure against gram-positive Staphylococcus aureus and gram-negative Eschirichia coli. Inhibition zone around the drug-incorporated hydrogel was compared after $24 \mathrm{~h}$ incubation at $37^{\circ} \mathrm{C}$, with a standard antibiotic disc as positive control and pHEMA-PCL-PEG hydrogel without drug as negative control (HI3). A minimum of 3 samples were tested in each case.

\section{Hemolysis Assay}

Hemocompatibility testing of hydrogel systems was carried out broadly on the basis of ISO 10993-4:2002(E) selection of tests for interaction of materials with blood. The test is mainly aimed at finding the extent of hemolysis caused by the sample. Blood from a healthy human volunteer was collected and the anticoagulant CPD-A was added as required. The samples kept in PBS were taken out and placed in polystyrene plates. Two $\mathrm{ml}$ of blood was added to each sample, one ml blood was taken immediately for initial analysis and $1 \mathrm{ml}$ blood was incubated with the samples for $30 \mathrm{~min}$ under agitation at $70 \pm 5 \mathrm{rpm}$ using an Environ shaker thermostated at $35 \pm 2^{\circ} \mathrm{C}$. Four empty polystyrene culture dishes were exposed with blood as reference. The total hemoglobin in the whole blood samples was measured using an automatic hematology analyzer (Sysmex-K 4500). The free hemoglobin liberated into the plasma after exposure to materials was measured using a diode array spectrophotometer (HP 8453 Hewlett-Packard GmbH, Germany) and the hemolysis percentage was calculated using the following formula:

$\%$ Hemolysis $=($ Free Hb/Total Hb $) \times 100$

\section{Cytotoxicity by direct contact assay}

An in vitro cytotoxicity test using the direct contact method was performed using fibroblast cells (Discarded foreskin) . Hdrg1 and control HI-3 samples were sterilized using ethylene oxide. The sterilized samples were then immersed in culture medium containing serum for $30 \mathrm{~min}$ prior to testing and placed on the cells (40000 cells $/ \mathrm{cm}^{2}$ ) and medium was replaced with fresh medium. After incubation at $37 \pm 1^{\circ} \mathrm{C}$ for $48 \mathrm{~h}$, the cell monolayer was imaged using optical microscope and Leica Application Suit software (Leica, DMIRB,Germany) at a magnification of $10 \mathrm{X}$.

\section{Cell viability study/Live dead assay}

Cell viability was analyzed by live-dead assay using acridine orange and ethidium bromide. Briefly, the fibroblast cells were cultured for $48 \mathrm{~h}$ in direct contact with the hydrogel matrix at $37^{\circ} \mathrm{C}$ in a humidified $\mathrm{CO}_{2}$ incubator in DMEM: HAM F12 medium containing $10 \%$ FBS. After $48 \mathrm{~h}$, the hydrogel was removed and the cells were washed with sterile PBS (thrice). Cells were incubated with acridine orange (1:100 dilution or $0.1 \mu \mathrm{g}$ $/ \mathrm{ml})$ and ethidium bromide (1:100 dilution $0.1 \mu \mathrm{g} / \mathrm{ml})$ in PBS at room temperature for $20 \mathrm{~min}$. Cells were washed with PBS thrice at 10-min intervals and images were captured using a fluorescent microscope and Leica Application Suit software (Leica, DMIRB,Germany) at a magnification of $10 \mathrm{X}$.

\section{Cell Adhesion study}

Hydrogel samples were seeded with a cell density of 70000 cells $/ \mathrm{cm}^{2}$ and allowed to attach for 72hours and then fixed with $3.7 \%$ formaldehyde for 20 minutes and then permeabilized with $0.2 \%$ triton X 100 (Molecular probes USA). Texas Red-conjugated antibodies (1:500) against actin cytoskeleton were added and kept at $37^{\circ} \mathrm{C}$ for $30 \mathrm{~min}$, washed thoroughly using PBS and observed through fluorescent microscope (Leica DMIRB, Germany) at a magnification of 20X. 


\section{RESULTS}

\section{Fabrication of the Ofloxacin-incorporated hydrogel} matrix

Photopolymerization at $380-480 \mathrm{~nm}$ of the drug containing monomer system was found to yield a hydrogel in which the drug was incorporated fully. Figure 1 shows the ofloxacin-incorporated swollen hydrogel sheet after the polymerization.

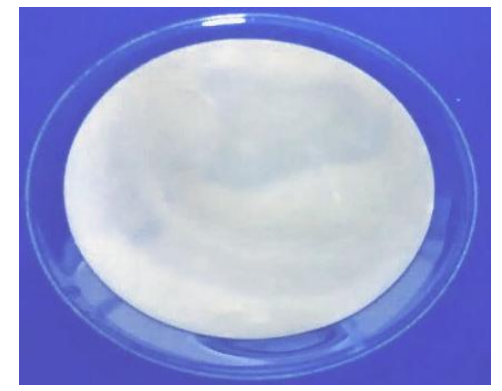

Figure 1: Ofloxacin-incorporated swollen hydrogel matrix (Hdrg)

Characterization of Ofloxacin-incorporated hydrogel matrix

\section{Swelling analysis}

To analyze the effect of incorporated drug on the fluid uptake ability of hydrogel system,swelling analysis was carried out in distilled water. The results of the swelling analysis of hydrogel systems are depicted in Figure 2. Comparative evaluation of swelling capacity indicated that fluid uptake ability of $\operatorname{Hdrg} 1(40 \pm 2 \%)$ was found to be significantly lower than that of HI-3(64 $\pm 2.8 \%)$.

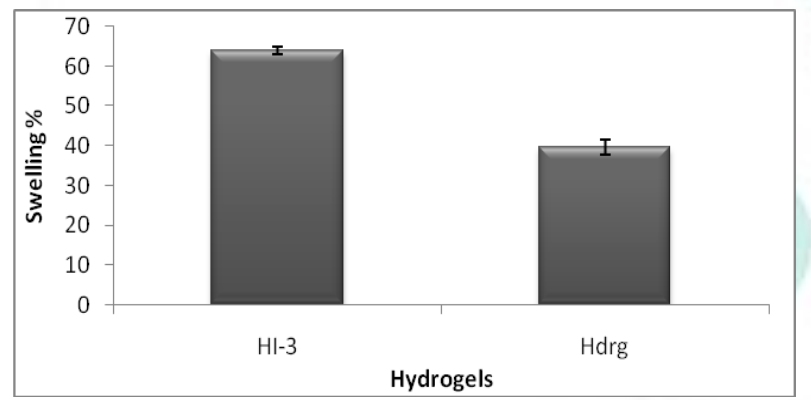

Figure 2: Swelling analysis of hydrogel systems
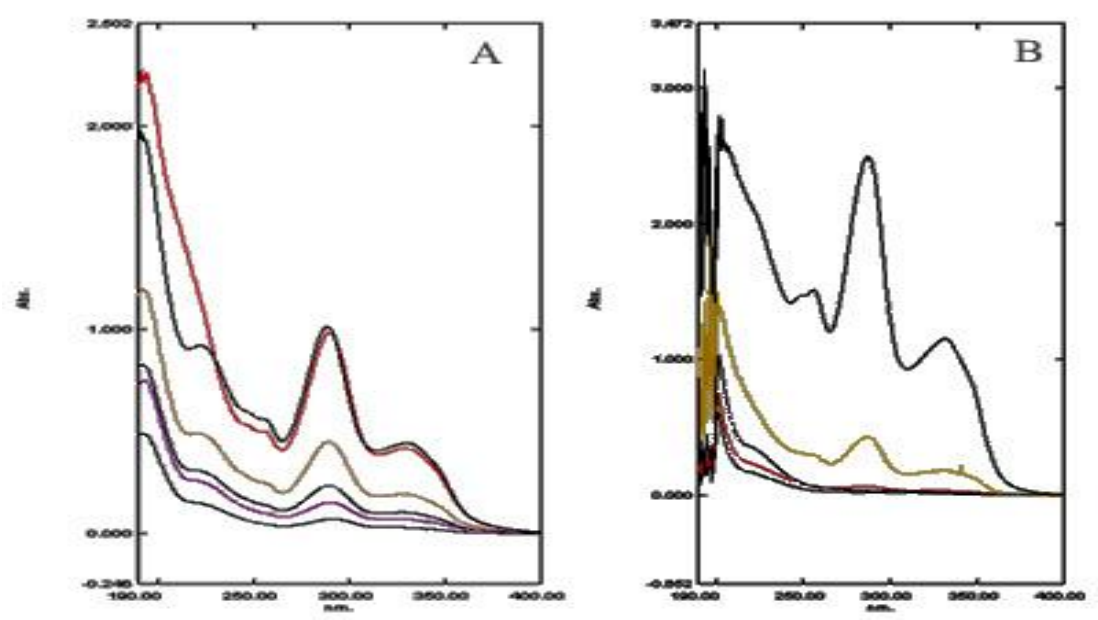

Figure 4: Release study of ofloxacin A) water B) PBS

\section{Surface Wettability Study}

The observed value of the contact angle of Hdrg1 was found to be $61 \pm 2{ }^{\circ}$. It was observed that addition of drug increased the surface hydrophobicity of the matrix compared to bare matrix HI-3 $\left(54 \pm 1^{\circ}\right)$.

\section{Drug Encapsulation Efficiency}

Evaluation of drug encapsulation efficiency is an important aspect, which provides a quantitative estimation of the actual drug within the hydrogel after formulation. UV spectroscopy technique was used for this study. Figure 3 depicts the UV absorption spectrum of Ofloxacin. Percentage encapsulation efficiency of ofloxacin in the hydrogel system was found to be nearly $60 \%$.

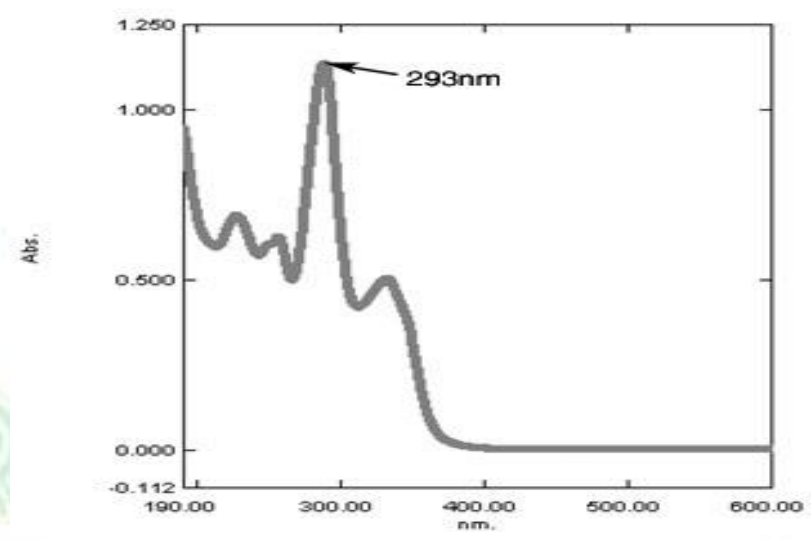

Figure 3: UV Absorbance spectrum of Ofloxacin

\section{In vitro release study of ofloxacin}

Effect of medium

Drug release study conducted in distilled water and PBS at $\mathrm{pH}=7.4$ demonstrated a faster drug release in PBS compared to water. The complete release of the drug from the matrix was completed in nearly $120 \mathrm{~h}$ in distilled water, whereas in PBS, sustained release was observed for $120 \mathrm{~h}$ after the initial burst release in the first 24 hrs (Figures $4 \mathrm{~A}$ and B). 
Effect of drug loading

Figure 5 displays the release profile of ofloxacin from hydrogels at different amounts of drug loading. The data shows that the hydrogel systems containing the highest amount of the drug exhibited a faster release rate than that of the systems with less drug loading. Hdrg1 showed a faster rate of drug release while Hdrg 0.25 displayed a slower rate of drug release.

\section{Antimicrobial property evaluation}

The antimicrobial property of the hydrogel matrix with different drug content was evaluated against grampositive (Staphylococcus aureus) and gram- negative (Escherichia coli) bacteria using the agar disc diffusion method. Figures 6 display zone of inhibition assay of Hdrg1 against Staphylococcus aureus and Escherichia Coli. The zone of inhibition of Hdrg1 was found to be similar with that of the control disc (Table 2).
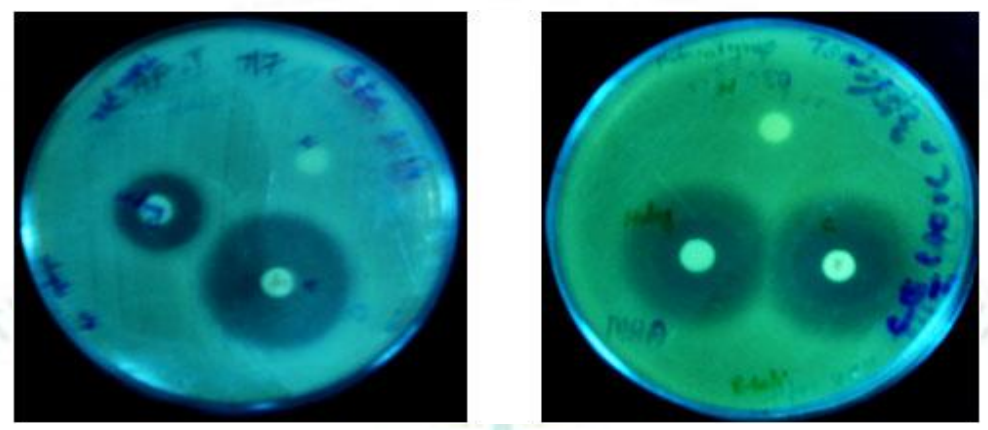

Figure 6: Representative patterns of zone of inhibition assay of Hdrg1 against (A) Staphylococcus aureus (B) Escherichia Coli. $(\mathbf{n} \geq 3)$

Table 2: Zone of inhibition of HI-3(negative control), Hdrg1 and Antibiotic drug (positive control) against S.aureus and E.Coli

\begin{tabular}{|l|l|l|}
\hline \multirow{2}{*}{ Samples } & \multicolumn{2}{|c|}{ Zone of inhibition } \\
\cline { 2 - 3 } & $\begin{array}{l}\text { S.Aureus ATCC } \\
\mathbf{2 5 9 2 3}\end{array}$ & $\begin{array}{l}\text { E.Coli ATCC } \\
\mathbf{2 5 9 2 2}\end{array}$ \\
\cline { 2 - 3 } & Unit 1 & Unit 1 \\
\hline HI-3 & Nil & Nil \\
\hline Hdrg1 & $12 \mathrm{~mm}$ & $20 \mathrm{~mm}$ \\
\hline Control & $33 \pm 0.5 \mathrm{~mm}$ & $20 \pm 1.5 \mathrm{~mm}$ \\
\hline
\end{tabular}

\section{Hemolysis Assay}

Hydrogel system without drug was found to be nonhemolytic. To study the effect of drug incorporation on

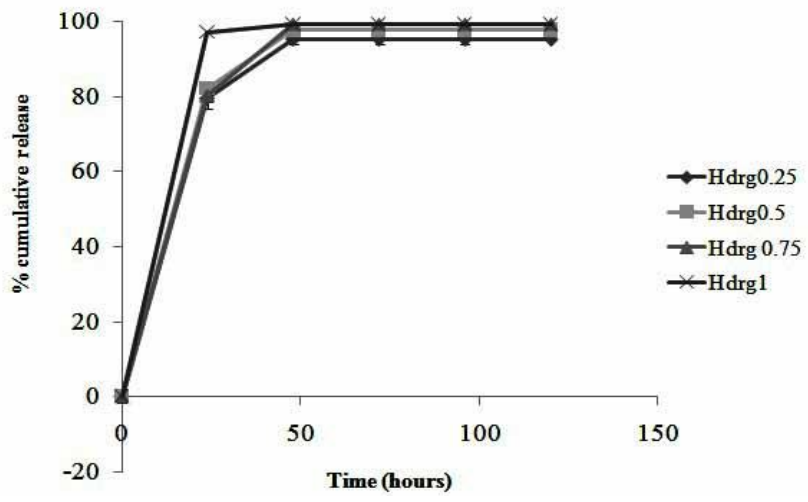

Figure 5: Cumulative release of drug from hydrogel systems with different drug loadings $(n \geq 3)$
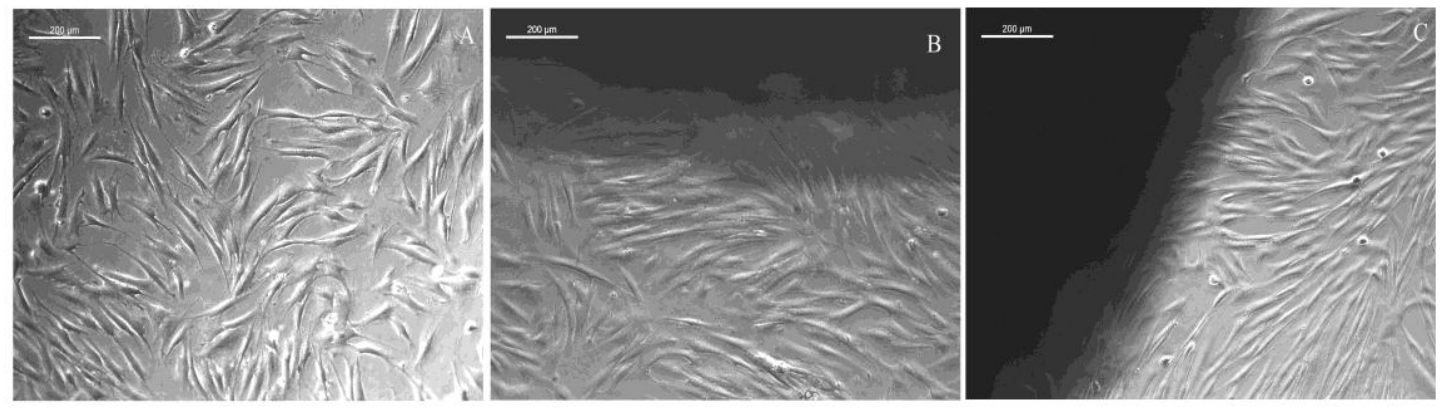

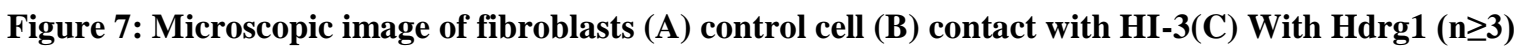


Cell viability

Acridine orange and ethidium bromide staining on fibroblast cells after incubation with Hdrg1 for 48 hours was conducted to evaluate the cell viability. Figures $8 \mathrm{~A}$ and B displays the fluorescent microscopic images of control fibroblasts and fibroblasts incubated with Hdrg1. Cell counting was carried out using Image $\mathbf{J}$ software and nearly $100 \%$ of the cells were found to be viable after incubation with Hdrg1 for $48 \mathrm{~h}$.

\section{Cell adhesion study}
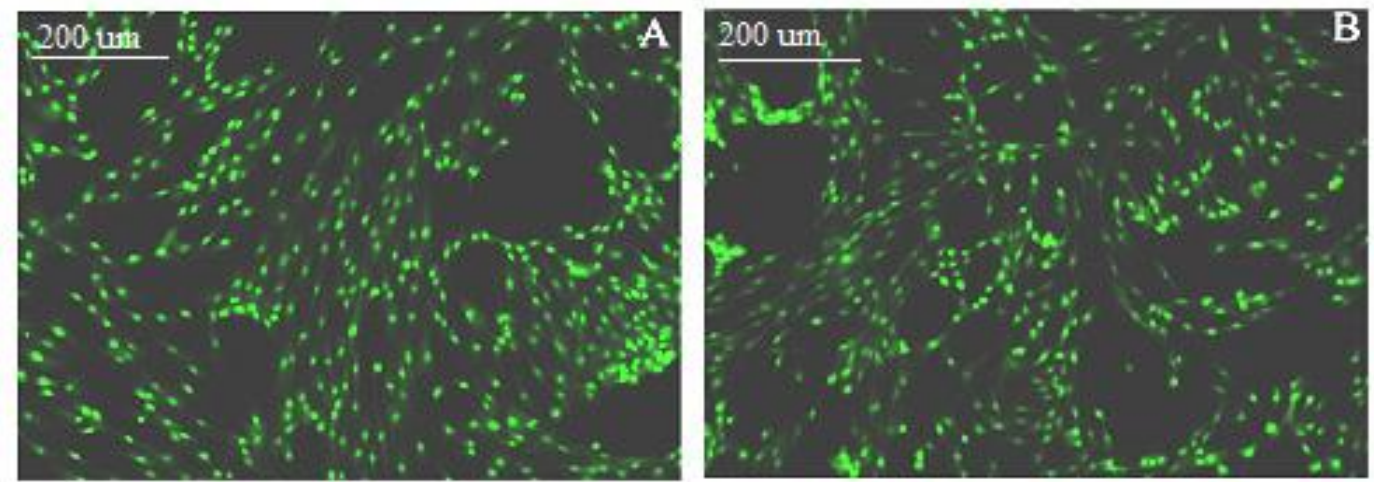

Figure 8: Live-dead assay using Acridine Orange and Ethidium Bromide on fibroblast cells, incubation at $37^{0} \mathrm{C}$

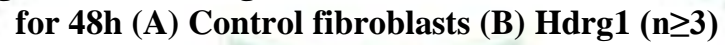
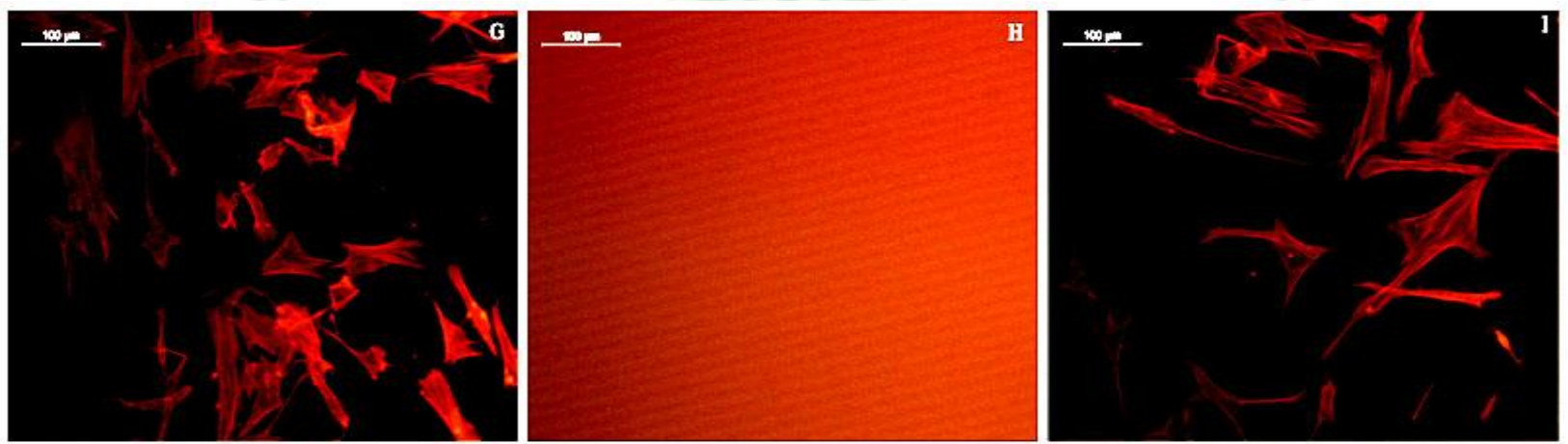

Figure 9: Microscopic images of actin staining on (G) Control fibroblast cells (H) Hdrg hydrogel (I) Fibroblast cells in contact with Hdrg1 $(n \geq 3)$

\section{DISCUSSION}

Various methods have been reported for preparing drugincorporated hydrogel matrices for biomedical applications. Song et al showed that effective incorporation of a drug can be achieved by incorporation of a drug in the monomer mixture along with the initiator and other additives and then allowing it to polymerize. ${ }^{11}$ In the present study, we have resorted to photo-polymerization technique successfully to prepare Hdrg (Figure 1) hydrogel by addition of a drug in the monomer HEMA containing PCL and PEG and a photoinitiator. The role of PCL and PEG in the hydrogel has been explained in detail in our earlier published data.$^{10}$ Ofloxacin has been found to be effective earlier in controlling skin structure infection caused by gramnegative and gram-positive aerobic bacteria. ${ }^{13}$ It is recommended that burn wound infections can be effectively reduced by the application of wound dressings incorporated with antibacterial agents rather than by applying topical ointments. The drug delivery system was developed for the purpose of bringing, taking up, retaining, and releasing the drug in right dose at the site. ${ }^{14,15}$ Various methods such as dipping or pasting have been adopted for incorporating the antibiotic agent silver sulphadiazine in pHEMA systems to develop antimicrobial burn wound dressings. However, long-term diffusion efficacy and fast elimination of the drug made these techniques ineffective. ${ }^{16}$ Thermal methods for impregnation and immobilization of antimicrobial agents onto pHEMA membranes have been reported earlier. ${ }^{17-19}$ Tsou et al used a UV irradiation technique to prepare poly (2hydroxy ethyl methacrylate) wound dressing systems incorporated with ciprofloxacin. ${ }^{7}$ 
Effect of incorporating the drug on swelling property compared to bare hydrogels can be observed in Figure 2. It is seen that incorporating ofloxacin tends to decrease the swelling rate of the hydrogel significantly and improve the hydrophobic character. The contact angle study also substantiates this observation. These results imply that the addition of the drug to the hydrogel system had an influence on its surface as well as on its bulk properties.

The drug encapsulation study indicates that nearly $60 \%$ drug is entrapped within the matrix effectively using the photo polymerization method. Figures 4 A \& B exhibit the burst release of the drug from the matrix within the first 24 hours in PBS compared to that in water. Nearly $85 \%$ of the drug was found to be released within 24 hours. Ions present in the PBS may have facilitated the burst release of drug from the matrix. Different drug loading on to the hydrogel matrix was done to evaluate its effect on drug release and antimicrobial effect. Figure 5 displays the release profile of drug from hydrogel at different drug loadings. Release data shows that formulations containing the highest amount of the drug displayed faster and higher release rates than those of the formulations with a lower amount of drug loading. The release rate becomes quite slower at the lower amount of drug in the matrix due to the availability of more free void space for the passage of the drug molecules.

Due to its broad spectrum of antibacterial activity, ofloxacin has been clinically proven earlier to be effective in controlling various infections such as skin and soft tissue infection, respiratory tract infections, urinary tract infections, etc. Figures $6 \mathrm{~A}$ and $\mathrm{B}$ show the clear inhibitory zones exhibited by the Hdrg1 against Gram-positive and Gram-negative bacteria. As can be seen from the size of the inhibitory zones (Table 2), similar antibacterial activity is exhibited by both sample and control against the E.coli strain. Figure 6A indicates that the antibacterial activity of Hdrg1 against S.aureus is less compared to control. The antibacterial effect of Hdrg1 is found to be more pronounced against Gramnegative bacteria than Gram-positive bacteria. Reports have proven that ofloxacin exhibits greater inhibitory action against gram-negative bacteria compared to grampositive bacteria.$^{20}$ Sato et al reported that ofloxacin is the most effective fluoroquinolone against staphylococci .$^{21}$ The antibacterial activity of the fluoroquinolone has been attributed to the inhibition of the A subunit of the enzyme DNA gyrase, which prevents the super coiling of bacterial DNA. Furthermore, ofloxacin may have an additional inhibitory effect on the $\mathrm{B}$ subunits of the enzyme.$^{20}$

Hemolytic property evaluation of Hdrg was carried out as per standard ISO 10993-4:2002 (E) and the results indicate that incorporation of ofloxacin in the matrix did not induce any hemolysis and the \% hemolysis $(1.56 \pm$ $0.3 \%$ ) was within the permissible level of $5 \%$. In vitro cytocompatibility evaluation using the direct contact test indicated that neither the released drug nor the drug within the matrix produced any unfavorable effect on the fibroblast growth. Figure 7C shows the microscopic image of well spread out, healthy spindle-shaped fibroblast cells in case of Hdrg1 comparable to fibroblast behavior found in HI-3(Figure 7B). Nearly $100 \%$ of the fibroblast cells were found to be viable after incubation with Hdrg1 for 48 hours (Figure 8B). The cell viability assay substantiated the in vitro cyotcompatibility property of Hdrg1. Cells underneath the hydrogel system were also found to maintain their spindle-shaped morphology with a well spread out nature (Figure 9I). These results validate the earlier non-cytotoxic property of the Hdrg1. Studies of actin staining indicated that the introduction of drug in the matrix does not produce any change in the non-cell adhesion property of the hydrogel system (Figure 9H).

\section{CONCLUSION}

Photopolymerization using a light source at 380-480nm was found effective in incorporating ofloxacin drug in a hydrogel system containing poly(HEMA) along with PCL and PEG. Incorporation of Ofloxacin at $1 \%$ level in the Hdrg1 hydrogel system was found to exhibit strong antimicrobial property as evidenced by zone of inhibition assay. Cytotoxic assessment by indirect contact method of Hdrg1 revealed the hydrogel noncytotoxic to fibroblasts. Fibroblasts were found not to adhere to the hydrogel while exhibiting improved cell proliferation. The hydrogel also exhibited good swelling, non-hemolytic character and optimum hydrophobic/hydrophilic balance for potential application as wound dressing.

\section{ACKNOWLEDGEMENTS:}

The authors wish to acknowledge the Director and Head (BMT Wing), SCTIMST for providing the facilities. One of the authors (RK) is grateful to Kerala State Council for Science, Technology and Environment, Kerala for fellowship support and part funding (KSCSTE and Burn Project 8042) during her doctoral program. This work forms part of the $\mathrm{PhD}$ work of one of the authors (RK)

\section{Conflict of Interest}

The authors have no potential conflicts of interest with respect to the research, authorship, and/or publication of this article. 


\section{REFERENCES}

1. Merlin G, Reinhard Z, Alexander EH, Andreas G, Mehimet A, Pietro G, Changes in bacterial isolates from burn wounds and their antibiograms: a 20 year study (1986-2005), Burns, 2009; 35(4):553-560.

2. Maneesh J, Asheesh G, Amit KD, Veena K. An investigation study of gelatin release from semi-interpenetrating polymeric network hydrogel patch for excision wound healing on Wistar rat model, Journal of Applied Polymer Science, 2015; 132(25):42120.

3. Huahong Z, Yanhang H, Jingchen G, Siyuan C, Yina M, Shufang W, A poly $(\gamma$-glutamic acid)-based hydrogel loaded with superoxide dismutase for wound healing, Journal of Applied Polymer Science, 2015; 132(23):42033.

4. Benjawan B, Pimpa S, Leila C, Philip MB, Pitt S, Hydrogels Containing Silver Nanoparticles for Burn Wounds Show Antimicrobial Activity Without Cytotoxicity, Journal of Applied Polymer Science, 2014; 131(9):40215.

5. Asheesh G, Nitin KU, Surekha P, Chitra R, Prasun KR, Nitrofurazone-loaded PVA-PEG semi-IPN for application as hydrogel dressing for normal and burn wounds, Journal of Applied Polymer Science, 2013; 128(6):4031-4039.

6. Thomas S, Hay $\mathrm{P}$, Fluid handling properties of hydrogel dressings, Ostomy wound management. 1995; 41(3):54-59.

7. Tsou TL, Tang ST, Huang YC,Wu JR, Young JJ, Wang HJ, Poly(2-hydroxyethyl methacrylate) wound dressing containing ciprofloxacin and its drug release, Journal Of Materials Science: Materials In Medicine, 2005; 16(2):95-100.

8. Ma L, Gao CY, Mao ZW, Shen J, Hu X, Han C, Collagen/chitosan porous scaffolds with improved biostability for skin tissue engineering, Bioamterials,2003; 24(26):48334841.

9. Azad AK, Sermsintham N, Chandrkrachang S, Stevens WF, Chitosan membrane as a wound-healing dressing: Characterization and clinical application, Journal of Biomedical Materials Research Part B,2004; 69B(2):216-22.

10. Rethikala PK, Krishnan VK, Photopolymerized poly(2hydroxyethyl methacrylate) / poly( $\varepsilon$-caprolactone) / poly(ethylene glycol) systemas a potential wound dressing material, Journal of Bioactive and Compatible Polymers, 2015; 30(1):74-86.

11. Song SZ, Cardinal JR, Kim SH, Kim SW, Progestin permeation through polymer membranes V: Progesterone release from monolithic hydrogel devices, J Pharmaceutical Sciences, 1981; 70(2):117-234.

12. Kallyanakrishnan V, Lissy KK, Rethikala PK, Indian Patent Application File No:201641026539 dated August 3,2016.

13. Kaushik R, Kumar S, Sharma R, Lal P, Bacteriology of burn wounds--the first three years in a new burn unit at the Medical College Chandigarh ,Burns, 2001; 27(6):595-7.

14. Langer R, New methods of drug delivery, Science 1990; 249:1527-1533.

15. Rathbone MJ, Witchey LL, Ciftci K, In Encyclopedia of controlled drug delivery; Mathiowitz E, Ed.; Wiley:New York, 1999; Vol 2, pp 1007-1037.

16. Fang C, Nathan P, Robb E C, Alexander JW, Macmillan BG, Prospective clinical study of Hydron, a synthetic dressing, in delivery of an antimicrobial drug to second-degree burns, Journal of Burn Care and Rehabilitation, 1987; 8(3):206-209.

17. Nathan P, Robb EC, Law EJ, Macmillan BG, A clinical study of antimicrobial agents delivered to burn wounds from a drug loaded synthetic dressing, Journal of Trauma. 1982; 22(12): 1015

18. Meslard JC, Yean L, Subira F, Vairon JP, Reversible immobilization of drugs in a hydrogel matrix ,Makromolecular Chemistry,1986; 187(4):787-794.

19. Tyagi PK, Gupta B, Singh H, Radiation induced grafting of 2hydroxyethylmethacrylate onto polypropylene for biomedical applications: II. Evaluation of Antimicrobial Suture, Journal of Macromolecular Science. 1993; 30(4):303.

20. Monk JP, Debora MCR, Ofloxacin :A review of its antibacterial activity, Pharmacokinetics properties and therapeutic uses, Drugs, 1987; 33(4):346-391.

21. Sato K, Inoue $\mathrm{Y}$, Fujii $\mathrm{T}$, Aoyama $\mathrm{H}$, Mitsuhashi $\mathrm{S}$, Antibacterial activity of ofloxacin and its mode of action, Infection, 1986; 14(4):S226-230 